\title{
Adjacent Segment Pathology: Much to Do About How Much Is Due to What We Do
}

Keywords: Adjacent Segment Degeneration, Adjacent Segment Disease, Cervical Spine Surgery, Cervical Disc Arthroplasty, Cervical Discectomy, Cervical Fusion

doi:10.1017/cjn.2016.293

Can J Neurol Sci. 2017; 44: 1-2

A few years ago, I was part of a study group on adjacent segment degeneration in the cervical spine. We suggested a change in terminology from "adjacent segment degeneration" to "adjacent segment pathology" (ASP) to reflect the fact that it was unclear how much of the changes seen in regions of the spine adjacent to surgical fusion are "iatrogenic" versus "degenerative" in nature. ${ }^{1}$ Are these findings a normal occurrence with age, or are they due to mechanical factors at play at the proximal and distal ends of a fusion? If it is the latter, how do we modify our interventions to decrease its incidence? This debate has been intensified in the past decade as long-term studies suggest lower rates of ASP and secondary procedures after cervical disc arthroplasty (CDA) versus traditional anterior cervical discectomy and fusion (ACDF). ${ }^{2}$ The following are my thoughts on the subject, with some reflections on the interesting work reported by Jack et $\mathrm{al}^{3}$ in this issue of The Journal.

There are three types of ASP: radiographic ASP (RASP), clinical ASP (CASP), and reoperation ASP (ReopASP). Just because you have radiographic evidence of ASP does not mean you necessarily have symptoms, and just because you have symptoms doesn't necessarily mean you need surgery. On the surface, this seems like a straightforward set of definitions. Unfortunately, there is substantial heterogeneity among studies because of variance in terms and their precise application. There are at least seven classification systems for ASP, but none is universally agreed upon, and they have not been tested for reliability or validity. ${ }^{4}$

As a result, a recent meta-analysis found the prevalence of RASP ranged from $4.74 \%$ to $92.22 \%$ across 35 studies and the prevalence of CASP ranged between $0 \%$ and $54.55 \%$ across 24 studies. ${ }^{5}$ You would think that a concept as clear as "reoperation" would provide more precise comparisons. However, there was still significant heterogeneity across 52 reports included in the meta-analysis, with ReopASP ranging from $0 \%$ to $16.90 \%$. $^{5}$

The length of follow-up certainly affects the prevalence of ASP, but not enough to account for this degree of variation. The development of RASP, CASP, and ReopASP is estimated to increase by $2.79 \%, 1.43 \%$, and $0.24 \%$ per year, respectively. ${ }^{5}$

Another confounding element in the analysis of ASP in the cervical spine is that it occurs most often at $\mathrm{C} 5 / 6$ or $\mathrm{C} 6 / 7$. As a result, patients who undergo a single-level procedure adjacent to these levels are at higher risk. This explains the paradoxically lower prevalence of ASP after multilevel cervical fusion that includes these levels in comparison to single-level fusion. ${ }^{5-7}$

With this background in mind, I would like to comment on the study by Jack et al. ${ }^{3}$ It is important to point out that, in this study,
ReopASP was used as a surrogate for CASP, which is a limitation of many retrospective studies.

Although most cervical fusion is performed in older patients with degenerative conditions, some occurs in other clinical settings. The hypothesis is that if ASP is largely secondary to natural age-related degeneration and is not the biomechanical effect of fusion, we should observe a lower rate of ASP in populations where these is a lesser degree of preexisting degeneration. Jack et $\mathrm{al}^{3}$ and others ${ }^{8-10}$ used a trauma cohort, and cervical ASP has also been studied in Klippel-Feil syndrome. ${ }^{11}$

The prevalence of RASP in the trauma cohort studied by Jack et al was only $1 / 32$ (3.1\%). This is remarkably low compared with other published trauma cohorts, which range from $5.2 \%$ at 2.5 years $^{8}$ to $60.0 \%$ at 7 years, ${ }^{10}$ but may be at least partially explained by the fact that radiologic follow-up was only 13 months. $^{3}$

Jack et $\mathrm{al}^{3}$ compared a trauma cohort to a degenerative cohort at their center, thus hopefully eliminating many of the problems with between-study comparisons. Unfortunately, there were still major differences between groups that likely introduced significant bias. The trauma group was overwhelmingly male and slightly younger than the degenerative group. Furthermore, the trauma group included some multilevel, posterior, and circumferential fusions, whereas the degenerative group was strictly single-level ACDF. There is evidence that posterior fusion significantly increases adjacent segment stress in comparison to anterior fusions. ${ }^{12}$ All patients in the degenerative group had imaging performed at a median 33 months postoperatively to evaluate for RASP, whereas only $70 \%$ of the trauma group had imaging done at a much shorter median 13 months postoperatively. Although the clinical follow-up (to assess ReopASP, which Jack et al call CSAP) was similar between groups (6.4 for trauma and 7.1 for degenerative), the difference did achieve statistical significance. Finally, patients in the trauma cohort but not the degenerative cohort were contacted by phone to see if they had undergone reoperation elsewhere. How much each of these factors may have biased the results one way or the other is debatable.

These differences between groups are only those that were obvious, based on the stated methods. Given the difference in the actual disease etiology (i.e. trauma vs. degenerative), there are likely to be other dissimilarities that are not measured or are frankly unknown. This is the sort of existential crisis a study starts to suffer from when you try to compare apples with oranges.

The most often cited clinical evidence for ASP not being a "fusion disease" does not wander out of the degenerative sphere.

Received July 18, 2016. Date of AcCeptance July 20, 2016. 
Gore $^{13}$ assessed the natural history of cervical spondylosis in 159 asymptomatic patients and found that $12 \%$ developed symptoms over 10 years. Herkowitz ${ }^{14}$ evaluated patients with cervical radiculopathy after ACDF or posterior foraminotomy without fusion. At a mean of 4.2 years, the rate of RASP was $39 \%$ after $\mathrm{ACDF}$ and $50 \%$ after foraminotomy at the operated or adjacent level.

In summary, the debate rages on. But despite the findings of Jack et $\mathrm{al}^{3}{ }^{3}$ the pendulum these days seems to be swinging in favor of the "iatrogenic" camp, ${ }^{15}$ as evidenced by the growing use of CDA. I think that this is somewhat misguided because ASP can complicate either ACDF or CDA. A recent meta-analysis by Shriver et al $^{16}$ reported that more than 2 years after CDA, the rate of RASP was $16.6 \%$ (range, $5.8 \%-27.4 \%$ ) and CASP \pm ReopASP was $2.6 \%(1.0 \%-4.2 \%)$.

To my mind, until the etiology and natural history of ASP is better understood, decision-making around the type of surgery (e.g. decompression, fusion, instrumentation, "motion-sparing device") should be largely dependent on factors other than ASP.

\section{Disclosures}

The author has nothing to disclose.

\section{Daryl R. Fourney \\ Division of Neurosurgery \\ University of Saskatchewan \\ Saskatoon, Saskatchewan, Canada \\ E-mail: daryl.fourney@usask.ca}

\section{REFERENCES}

1. Anderson PA, Andersson GB, Arnold PM, et al. Terminology. Spine. 2012;37:S8-9.

2. Hu Y, Lv G, Ren S, Johansen D. Mid- to long-term outcomes of cervical disc arthroplasty versus anterior cervical discectomy and fusion for treatment of symptomatic cervical disc disease: a systematic review and meta-analysis of eight prospective randomized controlled trials. PloS One. 2016;11:e0149312.
3. Jack A, Hardy St-Pierre G, Nataraj A. Adjacent segment pathology: progressive disease course or a product of iatrogenic fusion? Can J Neurol Sci. 2016. doi:dx.doi.org/10.1017/cjn.2016.293.

4. Kraemer P, Fehlings MG, Hashimoto R, et al. A systematic review of definitions and classification systems of adjacent segment pathology. Spine. 2012;37:S31-9.

5. Kong L, Cao J, Wang L, Shen Y. Prevalence of adjacent segment disease following cervical spine surgery: a PRISMA-compliant systematic review and meta-analysis. Medicine. 2016;95:e4171.

6. Hilibrand AS, Carlson GD, Palumbo MA, Jones PK, Bohlman HH. Radiculopathy and myelopathy at segments adjacent to the site of a previous anterior cervical arthrodesis. J Bone Jt Surg Am. 1999;81:519-28.

7. Lawrence BD, Hilibrand AS, Brodt ED, Dettori JR, Brodke DS. Predicting the risk of adjacent segment pathology in the cervical spine: a systematic review. Spine. 2012;37:S52-64.

8. Song KJ, Choi BW, Kim GH, Song JH. Usefulness of polyetheretherketone (PEEK) cage with plate augmentation for anterior arthrodesis in traumatic cervical spine injury. Spine J. 2010;10:50-7.

9. Koller H, Reynolds J, Zenner J, et al. Mid- to long-term outcome of instrumented anterior cervical fusion for subaxial injuries. Eur Spine J. 2009;18:630-53.

10. Goffin J, van Loon J, Van Calenbergh F, Plets C. Long-term results after anterior cervical fusion and osteosynthetic stabilization for fractures and/or dislocations of the cervical spine. J Spinal Disord. 1995;8:500-8; discussion 499.

11. Lee MJ, Dettori JR, Standaert CJ, Ely CG, Chapman JR. Indication for spinal fusion and the risk of adjacent segment pathology: does reason for fusion affect risk? A systematic review. Spine. 2012;37:S40-51.

12. Lee CK, Langrana NA. Lumbosacral spinal fusion. A biomechanical study. Spine. 1984;9:574-81.

13. Gore DR. Roentgenographic findings in the cervical spine in asymptomatic persons: a ten-year follow-up. Spine. 2001;26:2463-6.

14. Herkowitz HN. A comparison of anterior cervical fusion, cervical laminectomy, and cervical laminoplasty for the surgical management of multiple level spondylotic radiculopathy. Spine. 1988; 13:774-80

15. Lee MJ, Dettori JR, Standaert CJ, Brodt ED, Chapman JR. The natural history of degeneration of the lumbar and cervical spines: a systematic review. Spine. 2012;37:S18-30.

16. Shriver MF, Lubelski D, Sharma AM, Steinmetz MP, Benzel EC, Mroz TE. Adjacent segment degeneration and disease following cervical arthroplasty: a systematic review and meta-analysis. Spine J. 2016;16:168-81. 